HISTORIA: Jurnal Pendidik dan Peneliti Sejarah, 4(2), 95-102 DOI: https://doi.org/10.17509/historia.v4i2.25727

Available online at HISTORIA; Jurnal Pendidik dan Peneliti Sejarah
Journal homepage: https://ejournal.upi.edu/index.php/historia

\title{
DISKREPANSI KONSTRUKSI ILMU PENDIDIKAN SEJARAH DI INDONESIA DAN EROPA
}

\author{
Dea Lestari \\ Prodi. Pendidikan Sejarah, Universitas Negeri Jakarta \\ dealestari267@gmail.com
}

To cite this article: Lestari, D. (2021). Diskrepansi konstruksi ilmu pendidikan sejarah di indonesia dan eropa. HISTORIA: Jurnal Pendidik dan Peneliti Sejarah, 4(2), 95-102. https://doi.org/10.17509/historia.v4i2.25727.

Naskah diterima : 24 Juni 2020, Naskah direvisi : 7 Juni 2021, Naskah disetujui : 28 Juni 2021

\begin{abstract}
Regarding the construction of historical education, the initial question is, is it true that historical education is a science? So how is it different from history? Because the science of history education is closer to part of the educational sciences just like other educational sciences such as sociology education, geography education, and others. This paper aims to explain the differences in the construction of historical education in Indonesia and Europe. The research method used in this research is the descriptive qualitative method. Data collection techniques are mainly carried out in literature studies. This paper reveals the nature of education, placing humans as its primary focus. Human awareness of history needs to be built to maintain the existence of individuals, communities, or nations. The difference between history education and history education and in this paper also explains whether there are differences in historical education in Indonesia and Europe.
\end{abstract}

Keywords: Europe; History Education; Indonesia; Science Construction.

\begin{abstract}
Abstrak
Berkaitan dengan konstruksi ilmu pendidikan sejarah, pertanyaan awal adalah apakah benar bahwa pendidikan sejarah merupakan sebuah ilmu pengetahuan? Lalu apa bedanya dengan ilmu sejarah? Karena ilmu pendidikan sejarah lebih dekat kepada bagian dari ilmu-ilmu pendidikan sama seperti ilmu pendidikan lainnya seperti pendidikan sosiologi, pendidikan geografi, dan lain-lain. Tujuan dari tulisan ini adalah untuk menjelaskan perbedaan dari konstruksi ilmu pendidikan sejarah di Indonesia dan Eropa. Metode penelitian yang digunakan dalam penelitian ini adalah metode kualitatif deskriptif. Teknik pengumpulan data banyak dilakukan pada kajian literatur. Tulisan ini mengungkapkan hakekat pendidikan menempatkan manusia sebagai fokus utamanya. Kesadaran manusia akan sejarah menjadi hal yang perlu dibangun demi menjaga eksistensi pribadi, masyarakat ataupun bangsa. Perbedaan dari ilmu sejarah dan pendidikan sejarah dan dalam tulisan ini juga menjelaskan apakah terdapat perbedaan kedudukan ilmu pendidikan sejarah di Indonesia dan di Eropa.
\end{abstract}

Kata Kunci: Eropa; Indonesia; Konstruksi Ilmu; Pendidikan Sejarah. 


\section{PENDAHULUAN}

Pendidikan merupakan salah satu faktor yang terpenting dalam suatu negara. Kemajuan suatu negara sangat berkaitan dengan kemajuan tingkat pendidikan di negara tersebut. Hal tersebut terjadi karena pada dasarnya pendidikan bertujuan menghasilkan manusiamanusia unggul yang akan menjadi tulang punggung pembangunan suatu bangsa.

Pada hakekatnya pendidikan menempatkan manusia sebagai fokus utamanya. Kesadaran manusia akan sejarah menjadi hal yang perlu dibangun demi menjaga eksistensi pribadi, masyarakat ataupun bangsa. Kesadaran tersebut dapat tumbuh dan berkembang melalui pendidikan. Pengalaman suatu bangsa akan terus menjadi nilai atau karakter suatu bangsa bila tujuan mempelajari sejarah bukan hanya dibangun untuk memperoleh nilai saja tetapi juga bertujuan untuk menguatkan karakter setiap pribadi peserta didik melalui karakter bangsa.

Kesadaran akan pentingnya sejarah diwujudkan dalam pembelajaran yang dilaksanakan di sekolah. Mewajibkan setiap siswa yang mempelajari sejarah memiliki kualitas khusus yang perlu dikuasai yaitu pemahaman, kemampuan berpikir dan keterampilan sejarah. Pendidikan sejarah tidak saja menjadi wahana pengembangan kemampuan intelektual dan kebanggaan masa lampau, tetapi juga merupakan wahana dalam upaya memperbaiki kehidupan sosial budaya-politik, ekonomi, sosial, budaya yang berlangsung (Hasan,1999: 9).

"History has been written by the victors", ini adalah adagium yang pertama kali dikemukakan oleh Winston Churchill mengenai penulisan sejarah. Adagium ini bukan berarti membuat ilmu pengetahuan yang berkaitan dengan sejarah menjadi statis dalam arti karena sudah ditentukan oleh para pemenang (penguasa), adagium ini justru menjadi pemacu bagi ilmu-ilmu yang berkaitan dengan sejarah baik itu ilmu sejarah ataupun ilmu pendidikan sejarah untuk melakukan penelitian yang ilmiah terlepas dari pengaruh kekuaasaan karena ilmu pengetahuan bersifat independen.

Colingwood (1973) menegaskan bahwa sasaran penyususunan sejarah adalah untuk membentuk pemikiran agar kita dapat mengemukakan pertanyaanpertanyaan dan mencoba menemukan jawabanjawabannya. Oleh karena itu menurut Colingwood, "all history is the history of thought. Collingwood menyatakan bahwa, sejarah dapat dikatakan ilmiah karena dapat memberikan pemahaman kita terhadap pemikiran dari suatu peristiwa sejarah. Dengan ilmu sejarah, kita dapat memahami cara berpikir suatu tokoh dalam suatu peristiwa, menentukan apakah yang menyebabkan suatu peristiwa sejarah. Collingwood berpendapat bahwa, sejarah itu mengandung peristiwa unik dan di dalamnya dapat kita kategorikan sebagai studi untuk ilmu manusia karena kita dapat memahami suatu pemikiran manusia dalam peristiwa sejarah individu.

Wineburg (2007) mengungkapkan sejarah perlu diajarkan di sekolah karena memiliki potensi untuk menjadikan manusia lebih berkeperikemanusiaan, hal yang tidak dilakukan oleh semua kurikulum pembelajaran lainnya di sekolah. Tanpa sejarah, masa lalu hanya digunakan untuk kepentingan praktis saja dan kita menjadi terputus dari berbagai pengalaman kehidupan manusia (Lee, 1984).

Berkaitan dengan konstruksi ilmu pendidikan sejarah, pertanyaan awal adalah apakah benar bahwa pendidikan sejarah merupakan sebuah ilmu pengetahuan? Lalu apa bedanya dengan ilmu sejarah? Karena ilmu pendidikan sejarah lebih dekat kepada bagian dari ilmu-ilmu pendidikan sama seperti ilmu pendidikan lainnya seperti pendidikan sosiologi, pendidikan geografi, dan lain-lain.

Di Indonesia, setiap guru perlu memiliki standar kualifikasi pendidikan minimal S-1 sesuai dengan mata pelajaran yang akan diampunya. Apabila seseorang ingin menjadi guru sejarah, maka ia perlu untuk menjadi sarjana Pendidikan Sejarah. Namun kualifikasi ini belum tentu diterapkan di negara lain. Bahkan. Di Eropa, meskipun seseorang sudah mengambil Major ilmu sejarah dan minor ilmu pendidikan, tetap harus mengikuti training agar mampu menjadi guru sejarah.

Maka itu dalam artikel ini penulis mencoba untuk membahas diskrepansi konstruksi ilmu pendidikan sejarah di Indonesia dan Eropa agar dapat lebih memahami apa perbedaan kedudukan dari ilmu pendidikan sejarah di kedua negara tersebut.

\section{METODE}

Metode penelitian yang digunakan dalam penelitian ini adalah metode kualitatif deskriptif. Metode deskriptif yaitu diartikan sebagai teknik penuturan masalah secara detail, sistematis, dan berdasarkan data. Metode deskriptif kualitatif digunakan pada penelitian ini dimaksudkan untuk memperoleh informasi mengenai Diskrepansi Konstruksi Ilmu Pendidikan Sejarah Di Indonesia Dan Eropa secara mendalam dan komprehensif. (Mutiani, Abbas, E. W., Syaharuddin, Susant. H. 2020

Teknik pengumpulan data banyak dilakukan pada kajian litelatur. Prosedur pengolahan data dilakukan dengan mengumpulkan catatan lapangan, 
HISTORIA: Jurnal Pendidik dan Peneliti Sejarah, 4(2), 95-102 DOI: https://doi.org/10.17509/historia.v4i2.25727

menganalisis dan mengkategorikan dokumen dan menginterpretasikannya. Analisis data adalah proses mengorganisasikan dan mengurutkan data ke dalam pola, kategori dan satuan uraian dasar sehingga dapat ditemukan tema dan dapat dirumuskan hipotesis kerja seperti yang disarankan oleh data. Teknik analisis data yang dilakukan pada penelitian ini adalah dengan mengumpulkan dan mengorganisasikan dokumen yaang menunjang, kemudian menginput data, mengolah data dan menginterpretasikannya, terakhir menyajikan dalam bentuk deskriptif. Keabsahan data (trustworthiness) memiliki empat kriteria, yakni: kredibilitas atau derajat kepercayaan (credibility), keteralihan (transferability), kebergantungan (dependability) dan kepastian (confirmability).

\section{PEMBAHASAN}

\section{Konstruksi Ilmu Pendidikan Sejarah di Indonesia}

Proses pendidikan dan pembelajaran para calon guru sejarah di Indonesia dilaksanakan oleh kampuskampus atau Sekolah Tinggi yang memiliki program studi keguruan dan ilmu pendidikan, dalam prosesnya para calon guru ini memiliki dualisme keilmuan dalam arti ilmu pendidikan dan ilmu sejarah itu sendiri, konkritnya seperti yang terjadi di Program Studi Pendidikan Sejarah di Universitas Negeri Jakarta, dimana mahasiswanya diperbolehkan untuk menyusun skripsi dengan penelitian historis dimana penelitian tersebut adalah penelitian yang seharusnya dilakukan oleh mereka yang mengambil kuliah di Prodi Ilmu Sejarah, bukan Pendidikan Sejarah.

Tabel 1.1 Struktur Kurikulum UNJ

\begin{tabular}{lll}
\hline No & Kelompok & SKS \\
\hline 1. & Mata Kuliah Umum (MKU) & 13 \\
\hline 2. & $\begin{array}{l}\text { Mata Kuliah Dasar Kependidikan } \\
(\text { MKDK) 12 }\end{array}$ & 12 \\
\hline 3. & $\begin{array}{l}\text { Mata Kuliah Bidang Studi Dan Keah- } \\
\text { lian Penunjang (MKBK) }\end{array}$ & 104 \\
\hline 4. & $\begin{array}{l}\text { Mata Kuliah Ketrampilan Proses } \\
\text { Pembelajaran (MKKPP) }\end{array}$ & 15 \\
\hline & Total & 144 \\
\hline
\end{tabular}

Prodi Pendidikan Sejarah di UNJ yang dijadikan sebagai contoh, dimana dalam struktur kurikulum untuk mata kuliah kependidikan dan keterampilan pembelajaran jika dijumlah hanya 27 SKS dimana hal ini jauh berbeda dengan mata kuliah bidang studi yang berjumlah 104 SKS. Tabel 1.1 menggambarkan struktur kurikulum Prodi Pendidikan Sejarah UNJ.

Dari struktur kurikulum diatas dapat dipahami bahwa proses pendidikan guru di Indonesia bersifat concurrent atau terintegrasi dalam proses perkuliahan di S-1, hal ini juga yang menjadi pembeda dengan proses perkuliahan yang terdapat pada prodi Ilmu Sejarah yang tidak memiliki mata kuliah kependidikan ataupun pembelajaran seperti yang terdapat pada Prodi Ilmu Sejarah Universitas Indonesia.

\section{Membandingkan Pendidikan Sejarah dan Ilmu Sejarah}

Dapat kita pahami bahwasanya antara Ilmu Sejarah dan Pendidikan Sejarah berbeda, oleh karena secara epistemologis berbeda, maka fokus aktivitasnya pun sendiri-sendiri. Pendidikan Sejarah menekankan aktivitasnya pada pembelajaran, sedang Ilmu Sejarah berfokus pada penelitian. Pendidikan Sejarah memiliki hubungan yang erat dengan Ilmu Sejarah sebagai sumber utama pengetahuan akademik dalam proses pembelajaran sejarah.

Pendidikan Sejarah di Indonesia prosesnya dilaksanakan menggunakan model concurrent dimana pendidikan guru berlangsung secara integratif dengan semua perkuliahan seperti yang ada pada prodi-prodi pendidikan di kampus-kampus eks-IKIP, kalau dilihat dari modelnya apa yang terjadi di Indonesia sama seperti yang terjadi di Inggris. Contohnya pada University of Northampton dimana sistem pendidikan sejarah menggunakan model concurrent dan dilaksanakan selama 3 tahun. Berbeda dengan di Amerika Serikat yang menggunakan model consecutive, seperti yang terjadi di Ohio State University dimana para calon guru setelah mengambil S-1 Ilmu Sejarah diwajibkan mengambil kuliah lagi dalam program University Institute for Teaching and Learning (UITL), dalam program ini para calon guru diberi pendidikan untuk menjadi tenaga pengajar yang handal seperti tertuang dalam tujuan UITL.

Dalam bahasan diatas kita dapat memahami mengenai konstruksi Ilmu Pendidikan Sejarah di Indonesia yang berbeda dengan konstruksi Ilmu Sejarah walaupun diantara kedua disiplin ilmu memiliki keterkaitan yang cukup erat, hal ini dapat kita lihat dari tujuan dan proses pembelajaran yang dilakukan oleh masing-masing program studi dan terdapat perbedaan pola pada tiap negara.

\section{Eksistensi Ilmu Pendidikan Sejarah Setelah Diterapkannya Kebijakan Pendidikan Profesi Guru}

Pembelajaran Sejarah di Sekolah Menengah adalah untuk penguatan analogi dan eksplanasi. Oleh karena itu, 
di negara manapun, setiap negaranya pasti mempelajari sejarah bangsanya. Pendidikan sejarah merupakan salah satu mata pelajaran yang diajarkan di sekolah. Sebagai mata pelajaran wajib, sudah seharusnya Pendidikan Sejarah memiliki peran penting dalam membangun masyarakat Indonesia yang berkarakter. Berdasarkan sub-sub yang sudah dijabarkan sebelumnya, penulis mencoba menyimpulkan hakikat dan kedudukan pendidikan sejarah di Eropa.

Banyak kritik muncul terhadap kebijakan penyelenggaraan PPG, terutama dari para pakar pendidikan. Salah satu kritik yang muncul adalah bahwa jiwa pendidik tidak dapat ditanamkan dalam waktu singkat. Proses itu berlangsung dari sejak mahasiswa masuk pada semester pertama sampai dengan saat ujian tugas akhir. Taruhlah pandangan itu benar, pertanyaannya adalah bagaimana "jiwa pendidik" itu ditanamkan? Jawabannya tentu tidak dapat dengan alasan bahwa Pendidikan Belajar-Mengajar (PBM) disebar dari semester awal sampai akhir, karena berarti "jiwa pendidik" berada dalam mata kuliah-mata kuliah $\mathrm{PBM}$, sehingga hasilnya akan relatif sama antara disatukan menjadi 1 tahun atau disebar dalam banyak semester.

Kritik itu akan kuat apabila mampu ditunjukkan bahwa terdapat perbedaan yang signifikan antara mata kuliah-mata kuliah Bidang Studi (BS) di Pendidikan Sejarah dengan yang diajarkan di Ilmu Sejarah. Dengan kata lain, alasan yang dapat digunakan adalah bahwa pendidikan guru berlangsung integratif dengan semua perkuliahan atau yang dikenal sebagai model concurrent dan bukan consecutive. Diperlukan bukti yang kuat untuk mendukung pendapat bahwa pendidikan guru di Indonesia dewasa ini menggunakan model concurrent. Dari sudut pandang ini, pertanyaannya adalah adakah perbedaan esensial yang terkait pada isi antara mata kuliah Metode Sejarah, Sejarah Pergerakan Nasional, Sejarah Asia Timur dan sebagainya antara yang diajarkan di Pendidikan Sejarah dengan yang terdapat di Ilmu Sejarah? Dilihat dari silabus antara mata kuliah yang sama atau sejenis, sulit untuk mengatakan bahwa antara Pendidikan Sejarah dan Ilmu Sejarah terdapat perbedaan esensial yang signifikan.

Permasalahannya apakah berbagai kesamaan sungguh-sungguh yang dikehendaki oleh Pendidikan Sejarah sebagai cabang ilmu pengetahuan atau sekedar "salah jalan" yang terjadi pada prodi Pendidikan Sejarah? Apabila mata kuliah yang disusun dalam kurikulum sungguh-sungguh telah sesuai dengan tanggungjawab keilmuan pendidikan sejarah, berarti hubungan antara Ilmu Sejarah dengan Pendidikan Sejarah adalah dikodratkan bagaikan ibu dan anak. Dengan kata lain,
Pendidikan Sejarah merupakan hasil pengembangan/ penyederhanaan/adaptasi Ilmu Sejarah untuk tujuan pendidikan. Hubungan semacam itu mengingatkan pada definisi Ilmu Pengetahuan Sosial yang dipakai di Indonesia, yaitu sebagai penyederhanaan atau adapatasi dari disiplin ilmu-ilmu sosial dan humaniora, serta kegiatan dasar manusia yang diorganisasikan dan disajikan secara ilmiah dan pedagogis/psikologis untuk tujuan pendidikan. Meskipun demikian, nasib IPS jauh lebih buruk, karena pada tahun 2001 muncul kurikulum yang mengganti nama IPS menjadi Ilmu Sosial (G. Moedjanto pada Kompas 26 Mei 2003) Posisi sebagai adaptasi Ilmu Sejarah untuk tujuan pendidikan menjadikan sulit untuk mempertahankan pandangan bahwa pendidikan keguruan menggunakan model concurrent.

Realitas yang berlangsung sebagai praksis selama ini lebih mencerminkan bahwa proses pendidikan guru menggunakan model consecutive, yaitu dimulai dengan penguasaan disiplin ilmu tertentu sesuai mata pelajaran di sekolah menengah, lalu ditambah (plug-in) penguasaan kemampuan ilmu kependidikan. Dalam kondisi semacam itu, Pendidikan Sejarah akan selalu berada dalam posisi tergantung atau bahkan terhanyut dalam dinamika perkembangan Ilmu Sejarah. Contoh yang paling mudah adalah terdapatnya mata kuliah Pengantar Ilmu Sejarah. Mata kuliah itu sangat penting bagi mahasiswa Ilmu Sejarah, karena di dalamnya dikaji tentang hakekat dan kedudukan ilmu sejarah diantara ilmu-ilmu sosial dan humaniora lainnya.

Akan tetapi, akan menyedihkan apabila mata kuliah tersebut menjadi kurikulum inti Pendidikan Sejarah. Peserta didik pada Pendidikan Sejarah akan memahami dengan sangat baik hakekat dan kedudukan Ilmu Sejarah, sebaliknya sama sekali buta tentang hakekat dan kedudukan Pendidikan Sejarah. Ketergantungan dan keterhanyutan akan menjadikan Pendidikan Sejarah selalu berada dalam krisis, terutama adalah krisis identitas keilmuan. Dia tidak tahu siapa dirinya dan apa tanggungjawab atau tugasnya. Hal itu antara lain tampak dari tetap berlangsungnya PPG, meskipun berarti mencoreng muka dunia keguruan. Kondisi ini sangat membahayakan, tidak hanya bagi keberlangsungan PendidikanSejarah sendiri, tetapi juga bagigenerasi muda Indonesia pada umumnya. Mereka merasa Pendidikan Sejarah sebagai mata pelajaran yang membosankan dan tidak bermanfaat untuk mengembangkan kehidupan di masa sekarang.

Setiap ilmu memiliki karakteristik yang unik. Berdasar karakteristik tersebut ilmu pengetahuan dapat dibagi ke dalam tiga kelompok besar, yaitu ilmu-ilmu alam, ilmu-ilmu sosial dan humaniora. Ilmu-ilmu alam 
menempatkan benda-benda dan fenomena alam sebagai kajian dengan tujuan untuk menemukan hukumhukumnya, sehingga manusia dapat memanipulasinya demi peningkatan kenyamanan hidup. Ilmu-ilmu sosial dan humaniora memiliki subyek kajian yang sama, yaitu manusia. Perbedaannya, ilmu-ilmu sosial lebih fokus pada perilaku manusia, baik sebagai individu maupun sosial. Secara epistemologis, sejak memasuki jaman modern ilmu-ilmu sosial berusaha untuk menemukan pola dan hukum perilaku manusia. Berbeda dengan itu, humaniora berusaha memahami aspek kemanusiaan dari manusia dan mengembangkannya agar menjadi pribadi utuh. Pendidikan sebagai salah satu bagian dari Humaniora merupakan ilmu yang berusaha mengembangkan potensi-potensi manusiawi peserta didik baik potensi fisik potensi cipta, rasa, maupun karsanya, agar potensi itu menjadi nyata dan dapat berfungsi dalam perjalanan hidupnya.

Driyarkara dengan sangat cerdas merumuskan pendapatnya, bahwa pendidikan sebagai usaha pemanusiaan manusia muda. Pendidikan merupakan proses pengembangan generasi muda agar menjadi manusia seutuhnya, dalam arti dewasa lahir dan batin. Dari pengertian pendidikan dapat dipahami bahwa pada hakekatnya pendidikan menempatkan manusia sebagai fokus utama. Pendidikan, dalam konteks ini, merupakan proses pengembangan kesadaran diri peserta didik, tanpa harus mengalami sendiri pahitnya penderitaan, ketersingkiran, keterbuangan dan ketertekanan. Pendidikan Sejarah, sebagai bagian dari ilmu pendidikan, secara formal juga memiliki subyek kajian manusia, yaitu dalam pembentukan generasi muda yang berkesadaran atau sein.

\section{Pendidikan di Eropa}

Jerman

Pendidikan Sejarah adalah salah satu bidang pengajaran yang sangat terpengaruh dengan politik yang berkuasa di suatu negara. Salah satu contohnya, yaitu Pendidikan di Jerman. Jerman merupakan salah satu negara yang mempunyai "beban" sejarah terutama berkenaan dengan masa-masa Perang Dunia I dan Perang Dunia II. Kekalahan perang membuat Jerman terbelah menjadi Jerman Barat yang menganut sistem kapitalis dan Jerman Timur yang menganut sistem komunis.

Sistem pendidikan Jerman memiliki akar panjang hingga pada Abad Pertengahan di mana pendidikan merupakan lembaga yang banyak memengaruhi pendidikan warga di Jerman. Pengaruh gereja baru berkurang sejak abad ke-17 ketika secara resmi pendidikan dianggap tanggungjawab negara. Selain gereja pendidikan di Jerman juga sangat dipengaruhi oleh dua tradisi pengetahuan, yaitu humanisme dan naturalistime. Pandangan humanisme dan naturalistis ini didasarkan pada humanisme Humbold-seorang filsuf berpengaruh di Jerman. Utamanya adalah konsep Humbold tentang Bildung yaitu "pengertian rasional" tentang tatanan dunia.

Pandangan filosofis ini menekankan pada penyatuan pengetahuan akademik dengan pendidikan moral yang bersifat individualistis. Penekanan pada rasional tampak pada pentingnya matematika dan sains, sedangkan pendidik diharapkan juga bertindak sebagai pendidik moral bagi siswanya. Tradisi pengetahuan yang berkembang di Jerman tersebut berpengaruh pada sistem pendidikan Jerman yang mengenal sistem merefleksikan pandangan naturalistik di mana guru diharapkan menerapkan pendekatan berorientasi ke siswa dan menyiapkan mereka untuk melanjutkan pendidikan ke sekolah kejuruan, sementara Gymnasium merefleksikan pandangan humanistik.

Pelajaran sejarah merupakan pelajaran wajib yang diberikan kepada siswa dari grade 5/6-10 sebanyak dua jam pelajaran perminggu. Pelajaran sejarah ini pada praktiknya dapat pula dikombinasikan dengan pelajaran yang lain tergantung dari jenis sekolah. Pada kelas 1012/13 pelajaran sejarah tidak lagi menjadi pelajaran wajib. Pada grade 6-9 kurikulum sejarah disusun berdasarkan kronologis berkisar pada sejarah peradaban Barat. Pada grade 10 pelajaran sejarah berkaitan dengan sejarah kontemporer pada abad ke-20. Pada grade 1112/13 pelajaran sejarah difokuskan kepada sejarah Eropa modern dan sejarah non-Eropa seperti dekolonisasi dan topik-topik global lainnya.

Rusia

Wajib belajar di Federasi Rusia dimulai untuk semua anak pada usia enam atau tujuh dan berlangsung total sembilan tahun. Sebelum tahun 1984, sekolah dimulai pada usia tujuh dan durasi periode wajib belajar 10 tahun. Setiap orang tua bebas untuk memilih apakah ingin anak mereka untuk memasuki sistem pendidikan pada usia enam atau tujuh. Bagian utama dari tahap wajib pendidikan berlangsung empat tahun. Pendidikan menengah dibagi menjadi dua terdiri dari pendidikan menengah bawah dan pendidikan menengah atas sekunder yaitu sekolah menengah atau pendidikan umum tidak lengkap. Tahun ajaran dimulai pada awal September dan berlangsung sampai awal Juni.

Pendidikan menengah atas dibagi menjadi dua; akademik dan kejuruan/ teknis. Untuk akademik, siswa 
harus menyelesaikan studi pendidikan sekunder selama dua tahun (tingkat 10-11). Mereka menerima minimal 31 jam pelajaran setiap minggu, setelah menyelesaikan studi pendidikan sekunder, siswa harus diuji untuk mendapatkan penghargaan syarat masuk jenjang akademis.

Kurikulum sejarah Negara Federasi Rusia menetapkan standar sebagai satu set persyaratan wajib dalam pelaksanaan program pendidikan yang dilaksanakan oleh lembaga pendidikan dan standar tersebut terakreditasi negara. Standar ini didasarkan pada Konstitusi Federasi Rusia serta Konvensi PBB tentang Hak Anak dengan memperhitungkan kebutuhan regional, nasional dan etno-budaya dari masyarakat Federasi Rusia. Standar ini bertujuan untuk memberikan pembentukan identitas sipil siswa.

\section{Inggris}

Sejarah berdirinya Lembaga Pendidikan di United Kingdom atau Kerajaan Inggris yang saat lebih lebih akrab disebut dengan Inggris sudah mulai tercatat sejak akhir abad ke-6, yaitu dalam periode sejarah Inggris Anglo-Saxon. Sekolah yang diperkirakan pertama berdiri di Inggris adalah sebuah grammar school yang didirikan tahun 598 di Centerbury, England. Pendidikan di Inggris menjadi rujukan pertama bagi beberapa universitas di berbagai negara di dunia. Universitas Oxford adalah satu-satunya universitas pertama dan tertua di Inggris, dengan dibuktikan mulai adanya pembelajaran sejak tahun 1096 dan mulai berkembang dengan pesat pada tahun 1167 . Kemudian pada tahun 1209, beberapa ahli dan ilmuan memutuskan untuk pindah dari Oxford ke Cambridge, yang kemudian menjadi cikal bakal berdirinya Universitas Cambridge. Setiap negara bagian memiliki bagian Pendidikan yang bertanggung jawab atas Pendidikan, meskipun disebut nasional tapi dilaksanakan secara local (national system, locally administered).

Sejarah merupakan pelajaran yang diajarkan kepada peserta didik di Inggris sejak stage 1 hingga stage 3. Sebuah Pendidikan sejarah yang berkualitas tinggi melengkapi siswa untuk berpikir kritis, mempertimbangkan bukti, menyaring argument, dan mengembangkan perspektif dan pertimbangan. Sebuah pengetahuan tentang masa lalu Inggris, tempat kita di dunia, membantu kita memahami tantangan zaman.

\section{Hakikat Pendidikan Sejarah di Eropa}

Sebagai sebuah ilmu, Negara - Negara di Eropa memiliki berbagai universitas yang menyediakan Program Studi Ilmu Sejarah dan Pendidikan Sejarah sebagai salah satu pilihannya. Namun untuk menjadi guru sejarah di Eropa, guru harus sudah pernah mempelajari sejarah di Universitas entah itu sebagai ilmu major atau minor. Namun ada juga universitas yang menyediakan jurusan sejarah dengan pendekatan mengajar untuk anak sekolah menengah. Kebanyakan jurusan pendidikan ilmu sosial disediakan pada level magister.

Dilematisasi Pendidikan Sejarah sebagai ilmu atau anak ilmu atau cabang ilmu dari ilmu pendidikan atau ilmu sejarah menghasilkan tugas - tugas diskusi solusi atas permasalahan ini, perlu untuk mengkaji ulang makna Pendidikan Sejarah. Namun di Eropa setiap guru benar - benar diseleksi dengan baik karena sistem yang dibuat sudah diatur dan dijalankan sesuai aturan. Jadi, kebingungan antara Pendidikan Sejarah dengan Ilmu Sejarah sudah memiliki batasannya masing-masing.

Tabel 1.2 Program Studi Pendidikan Sejarah di Eropa

\begin{tabular}{lll}
\hline No & Universitas & \multicolumn{1}{c}{ Program Studi } \\
\hline 1. & Jerman & $\begin{array}{l}\text { Kebanyakan universitas di Jerman } \\
\text { memiliki program studi sejarah. }\end{array}$ \\
& & Namun untuk yang membuka \\
& studi sejarah sekaligus Pendidikan/ \\
& & Pendidikan sejarah belum \\
& ditemukan. \\
& & Kebanyakan Universitas di Inggris \\
& memiliki program studi sejarah. \\
& Yang membuka program studi \\
& & Pendidikan sejarah hanya ada \\
& & beberapa universitas saja, yaitu: \\
& 1. University of Northampton \\
& 2. Aberystwyth University \\
& 3. University of Sunderland \\
& -History/Education Studies BA \\
& (Hons) \\
& -History/Education BA (Hons) \\
& -Secondary History Education \\
\hline 3. & Kebanyakan universitas di Rusia \\
& memiliki program studi sejarah. \\
& Namun untuk yang membuka \\
& studi sejarah sekaligus pendidikan \\
& belum ditemukan. \\
\hline &
\end{tabular}

Dari tabel tersebut dapat dilihat, jika beberapa perguruan tinggi di Eropa ada yang memiliki program studi ilmu sejarah dan ada juga beberapa yang memiliki program studi pendidikan sejarah. Salah satu perguruan tinggi yang memiliki program studi Pendidikan Sejarah di Eropa, yaitu Northampton University. Di Northampton University, program studi pendidikan 
HISTORIA: Jurnal Pendidik dan Peneliti Sejarah, 4(2), 95-102 DOI: https://doi.org/10.17509/historia.v4i2.25727

Tabel 1.3 Materi Pokok Yang Dipelajari Prodi Pendidikan Sejarah di Northamton University

\begin{tabular}{|c|c|c|}
\hline Tahap 1 & Tahap 2 & Tahap 3 \\
\hline $\begin{array}{l}\text { Anda akan diperkenalkan dengan } \\
\text { disiplin ilmu inti yang mendukung } \\
\text { analisis akademik dari kedua } \\
\text { subjek. Anda akan mempelajari } \\
\text { berbagai pendekatan, persepsi, } \\
\text { dan sumber daya teoretis untuk } \\
\text { memahami dan menjelaskan aspek } \\
\text { Kebijakan Pendidikan, Keragaman } \\
\text { Sosial dan Inklusi. Modul juga } \\
\text { akan mengeksplorasi Sejarah Eropa } \\
\text { modern awal c1500-1700, Sejarah }\end{array}$ & $\begin{array}{l}\text { Anda memiliki pilihan untuk mempelajari } \\
\text { berbagai macam modul. Jika Anda ingin } \\
\text { menjadi Guru Sejarah di Sekolah Menengah } \\
\text { harus mempertimbangkan mengambil } \\
\text { jurusan Sejarah untuk menunjukkan bukti } \\
\text { pengetahuan subjek spesialis, dalam hal } \\
\text { ini mereka harus mengambil Keterampilan } \\
\text { Penelitian dalam Sejarah dan tiga modul } \\
\text { lainnya, Anda kemudian perlu memilih dua } \\
\text { modul yang ditunjuk dalam Pendidikan } \\
\text { Studi }\end{array}$ & $\begin{array}{l}\text { Anda akan memiliki kesempatan untuk } \\
\text { mengembangkan studi khusus dan } \\
\text { intensif di bidang dan aspek Sejarah dan } \\
\text { Studi Pendidikan yang menurut Anda } \\
\text { menarik. Anda akan membuat disertasi } \\
\text { yang memungkinkan Anda untuk } \\
\text { menyelidiki bidang minat pribadi atau } \\
\text { karier. Siswa yang memiliki perpecahan } \\
\text { genap pada program mereka dapat } \\
\text { memilih untuk menulis disertasi di salah } \\
\text { satu mata pelajaran mereka. }\end{array}$ \\
\hline
\end{tabular}

\begin{tabular}{|c|c|c|c|c|c|}
\hline 1 , & $\begin{array}{l}\text { Recent and Contemporary } \\
\text { Education Issues (20 Credits) }\end{array}$ & $\begin{array}{l}1 . \\
2 .\end{array}$ & $\begin{array}{l}\text { Debates in Education ( } 20 \text { Credits) } \\
\text { Young People and Society Part } 1 \text { (SEN and }\end{array}$ & 1. & $\begin{array}{l}\text { Education Studies Dissertation }(40 \\
\text { Credits) }\end{array}$ \\
\hline 2. & $\begin{array}{l}\text { Introduction to Education Studies } \\
\text { Part A ( } 10 \text { Credits) }\end{array}$ & 3. & $\begin{array}{l}\text { Inclusion) ( } 20 \text { Credits) } \\
\text { Education and Heritage ( } 20 \text { Credits) }\end{array}$ & 2. & $\begin{array}{l}\text { Education Studies Research Report ( } 20 \\
\text { Credits) }\end{array}$ \\
\hline 3. & $\begin{array}{l}\text { Introduction to Education Studies } \\
\text { Part B (10 Credits) }\end{array}$ & 4. & $\begin{array}{l}\text { Learning Through Educational Visits and } \\
\text { Exchanges ( } 20 \text { Credits) }\end{array}$ & 3. & $\begin{array}{l}\text { Education Studies Joint Dissertation ( } 20 \\
\text { Credits) }\end{array}$ \\
\hline 4. & $\begin{array}{l}\text { Education in a Global Context }(20 \\
\text { Credits) }\end{array}$ & 5. & $\begin{array}{l}\text { The Psychology of Learning and Teaching in } \\
\text { Educational Settings ( } 20 \text { Credits) }\end{array}$ & 4. & $\begin{array}{l}\text { Education, Culture and Society ( } 20 \\
\text { Credits) }\end{array}$ \\
\hline 5. & $\begin{array}{l}\text { Themes and Perspectives in } \\
\text { History ( } 20 \text { Credits) }\end{array}$ & 6. & $\begin{array}{l}\text { Research Methods (Childhood and Youth } \\
\text { and Education) ( } 20 \text { Credits) }\end{array}$ & 5. & $\begin{array}{l}\text { Issues of Equality in Educational } \\
\text { Settings (20 Credits) }\end{array}$ \\
\hline 6. & $\begin{array}{l}\text { The Holocaust: Source and } \\
\text { Contexts ( } 20 \text { Credits) }\end{array}$ & $\begin{array}{l}7 . \\
8 .\end{array}$ & $\begin{array}{l}\text { History of Childhood ( } 20 \text { Credits) } \\
\text { Transitions for Children, Young People and }\end{array}$ & 6 & $\begin{array}{l}\text { Critical Perspectives on Current } \\
\text { Education Practices (20 Credits) }\end{array}$ \\
\hline 7. & $\begin{array}{l}\text { Early Modern Europe } 1500-1800 \\
\text { (20 Credits) }\end{array}$ & $\begin{array}{l}9 . \\
10 .\end{array}$ & $\begin{array}{l}\text { Families ( } 20 \text { Credits) } \\
\text { Research Skills in History ( } 20 \text { Credits) } \\
\text { Power and Protest: British Society in the }\end{array}$ & 7. & $\begin{array}{l}\text { Emancipatory Approaches in Working } \\
\text { with Children and Young People ( } 20 \\
\text { Credits) }\end{array}$ \\
\hline & & & Long Eighteenth-Century (20 Credits) & 8. & Exploring Deviance and Disaffection \\
\hline & & $\begin{array}{l}11 . \\
12 .\end{array}$ & $\begin{array}{l}\text { Empire Through History ( } 20 \text { Credits) } \\
\text { Crime, Policing and Punishment in England } \\
1700-1900 \text { ( } 20 \text { Credits) }\end{array}$ & 9. & $\begin{array}{l}\text { Crime and Popular Culture in the late } \\
\text { Nineteenth Century City (20 Credits) }\end{array}$ \\
\hline & & 13 & $\begin{array}{l}\text { Comrades and Revolutions! A Global } \\
\text { History of the Communist Movement }(20\end{array}$ & 10 & $\begin{array}{l}\text { Movements and Regimes: A Century of } \\
\text { Fascism ( } 20 \text { Credits) }\end{array}$ \\
\hline & & & Credits) & 11. & Child and Adolescent Mental Health (20 \\
\hline & & 14 & First World War (20 Credits) & & Credits) \\
\hline & & 15 & $\begin{array}{l}\text { Family and Life-Cycles in Early Modern } \\
\text { England ( } 20 \text { Credits) }\end{array}$ & 12. & $\begin{array}{l}\text { Educational Aims Value and Ethics (20 } \\
\text { Credits) }\end{array}$ \\
\hline & & 16 & 'Decline and Fall': The English Aristocracy, & 13. & History Dissertation (40 Credits) \\
\hline & & & 1750-1950 (20 Credits) & 14. & History Dissertation (20 Credits) \\
\hline & & & & 15 & History Joint Dissertation (20 Credits) \\
\hline & & & & 16. & $\begin{array}{l}\text { Citizenship and Gender in Britain 1760- } \\
1918 \text { (20 Credits) }\end{array}$ \\
\hline & & & & 17. & $\begin{array}{l}\text { Witchcraft and Heresy in Early Modern } \\
\text { Europe ( } 20 \text { Credits) }\end{array}$ \\
\hline & & & & & $\begin{array}{l}\text { Secret State: British Intelligence, 1558- } \\
1945 \text { (20 Credits) }\end{array}$ \\
\hline & & & & 19. & $\begin{array}{l}\text { The English Country House, c.1660- } \\
1830 \text { (20 Credits) }\end{array}$ \\
\hline & & & & 20. & $\begin{array}{l}\text { Women and Gender in Early Modern } \\
\text { England ( } 20 \text { Credits) }\end{array}$ \\
\hline & & & & & $\begin{array}{l}\text { Algeria: French Rule and the War for } \\
\text { Independence ( } 20 \text { Credits) }\end{array}$ \\
\hline & & & & 22. & $\begin{array}{l}\text { Death and Bereavement in Britain, c. } \\
1500-1914 \text { (20 Credits) }\end{array}$ \\
\hline
\end{tabular}


sejarah masuk ke fakultas sejarah atau bisa dibilang masuk ke golongan ilmu sejarah, berbeda halnya dengan Indonesia yang masuk ke fakultas ilmu pendidikan yang basic nya lebih ke pendidikan dibanding dengan ilmu sejarahnya. Hal tersebut dapat dilihat dari tabel 1.3.

\section{SIMPULAN}

Dapat kita pahami bahwasanya antara Ilmu Sejarah dan Pendidikan Sejarah berbeda, oleh karena secara epistemologis berbeda, maka fokus aktivitasnya pun sendiri-sendiri. Pendidikan Sejarah menekankan aktivitasnya pada pembelajaran, sedang Ilmu Sejarah berfokus pada penelitian. Pendidikan Sejarah memiliki hubungan yang erat dengan Ilmu Sejarah sebagai sumber utama pengetahuan akademik dalam proses pembelajaran sejarah.

Perguruan Tinggi di Eropa ada yang memiliki program studi ilmu sejarah dan ada juga beberapa yang memiliki program studi pendidikan sejarah. Salah satu perguruan tinggi yang memiliki program studi Pendidikan Sejarah di Eropa, yaitu Northampton University. Di Northampton University, program studi pendidikan sejarah masuk ke fakultas sejarah atau bisa dibilang masuk ke golongan ilmu sejarah, berbeda halnya dengan Indonesia yang masuk ke fakultas ilmu pendidikan yang basic nya lebih ke pendidikan dibanding dengan ilmu sejarahnya.

\section{REFERENSI}

Bertens, K. (2014). Filsafat barat kontemporer jilid I (Inggris dan Jerman). Jakarta: Gramedia

Collingwood, R.G. (1973). The Historical Imagination" Cetak ulang dalam bukunya The Idea of History, Oxford.

Goodson, I. F., \& Lindblad, S. (Eds.). (2011). Professional knowledge and educational restructuring in Europe (Vol. 4). Springer Science \& Business Media.
Hasan, S.H. (1999). Pendidikan sejarah untuk membangun manusia baru indonesia. dalam Mimbar Pendidikan, 18(2), 4-11.

Jubaedah, S. (2019). Kurikulum pendidikan sejarah di inggris. Syntax Literate; Jurnal Ilmiah Indonesia, 3(12), 138-150.

Kurniawati, K. (2015). Pendidikan sejarah dalam kurikulum di republik federal jerman. Jurnal Pendidikan Sejarah, 4(1), 1-3.

Lee, P.J. (1984). Learning history. Liverpool (Britain): Heineman Educational Book

Marli, S. (2012). Sejarah dan pendidikan sejarah. Jurnal Cakrawala Kependidikan, 9(2).

Mutiani, Abbas, E. W., Syaharuddin, Susant. H. (2020). membangun komunitas belajar melalui lesson study model transcript based learning analysis. HISTORIA: Jurnal Pendidik dan Peneliti Sejarah, 3 (2). 2020. 113-122.

Purwanta, H. (2019). Hakekat pendidikan sejarah. Surakarta: UNS Press dan Chers.

Quthb, M. (1993). Sistem pendidikan. core.ac.uk

Schissler, H., \& Soysal, Y. N. (Eds.). (2005). The nation, Europe, and the world: Textbooks and curricula in transition. Berghahn Books.

Supriatna, N. (2011). Konstruksi pembelajaran sejarah yang berorentasi pada masalah kontemporer pembangunan. MIMBAR: Jurnal Sosial Dan Pembangunan, 27(1), 21-30. https://doi. org/10.29313/mimbar.v27i1.308

Wineburg, S. (2007). Berpikir historis: memetakan masa depan, mengajarkan masa lalu. Jakarta: Yayasan Obor Indonesia.

Internet:

Website: Northampton.ac.uk 